\title{
Exploration of ICT Appropriation by Disabled People and Its Effect on Self-Perceived Normalcy:
} Insights From France

\author{
Sarah Richard, EM Strabourg Business School, France \\ Daria Plotkina, EM Strasbourg Business School, France \\ Hélène Saurel, University of Tours, France*
}

\begin{abstract}
Information and communication technologies (ICTs) are omnipresent and define the interactions in society. Within society, there are vulnerable groups of people for whom ICT use is more challenging. Disabled people are the most vulnerable ICT users. To identify the digital divides of access and impact of ICT on disabled users, an exploratory qualitative study was conducted. Relying on a French national association for disability that grants unique access to disabled ICT users, two focus groups and 10 in-depth interviews were carried. The study proposes a model of ICT use and its effects for disabled people, integrating several types of disabilities. The results show that ICT appropriation by disabled users depends on their perceived self-efficacy in ICT. ICT use can lead to negative effects, including social exclusion and low perceived normalcy. To address societal interests and develop the literature, a research agenda is proposed.
\end{abstract}

\section{KEYWORDS}

Digital Divide, Disability, ICT Appropriation, Self-Perceived Normalcy, Vulnerability

\section{INTRODUCTION}

The modern world has been transformed by information and communication technologies (ICTs). ICTs are Internet-related "technologies that are used for accessing, gathering, manipulating and presenting or communicating information" (Toomey, 2001, para. 3). ICTs, such as Internet and other digital technologies, can bring multiple opportunities and benefits for people (Michel-Verkerke, Schuring, \& Spil, 2005).

In Europe, ICTs have developed as well. They have long been recognized by European institutions as enablers of socio-economic progress, but the benefits of ICT are still not fully realized in every territory (e.g., rural areas) and for every citizen (e.g., the poor or the elderly do not easily benefit from ICT development). Thus, European institutions have taken actions to ensure that ICT should benefit to the greatest number of citizens. They support and fund ICT projects that aim to tackle important societal challenges defined in the Horizon 2020 European program, such as inequalities and exclusion.

Restricted access and usage of ICT is referred to as the digital divide and constitutes a social inequality (Ragnedda \& Muschert, 2013). Barriers to the access and use of ICT lead to inaccessibility of crucial goods and services, social exclusion, and increased vulnerability. Among the most 
vulnerable with regard to the digital divide are disabled people (Doh \& Stough, 2010). According to the Convention on the Right of Persons with Disabilities (CRPD), disabled people are "those who have long-term physical, mental, cognitive or sensory impairments which in interaction with various barriers may hinder their full and effective participation in society on an equal basis with others" (Art. 1, CRPD). More than 42 million European citizens are affected by a disability (Grammenos, 2018).

Indeed, ICT appropriation by disabled people is a major and growing issue (Chadwick, Quinn \& Fullwood, 2016; Yu, Goggin, Fisher \& Li, 2019). However, in spite of all legal actions that have been taken to ensure technology accessibility to disabled people, national statistics in some European countries show that disabled people use less ICT than non-disabled people. In European countries, only $52.2 \%$ of disabled people have home access to the Internet, compared to $73.6 \%$ for non-disabled adults (Scholz, Yalcin, \& Priestley, 2017). Academic results have also confirmed that disabled people use less ICT than non-disabled people due to a lack of skills in ICT usage and to a lack of Internet access and equipment (Doh \& Stough, 2010). As a consequence, disabled people might feel excluded from society and experience a reduced self-perception of normalcy (Baker, 2006).

Several gaps have been identified in the literature. First, existing ICT literature offers general frameworks on ICT appropriation that study ICT access and usage (van Deursen \& van Dijk, 2015). However, few works apply these frameworks to disabled users (Doh \& Stough, 2010). Disabled users might have specific ICT user experiences. Second, while existing frameworks focus on ICT access and usage (van Deursen \& van Dijk, 2015), few studies have examined the consequences of disabled people ICT appropriation (Blank \& Groselj, 2014). Third, existing findings on the topic are contradictory, showing both positive and negative outcomes (Darcy, Yerbury \& Maxwell, 2019; Elms \& Tinson, 2012; Kaufman-Scarborough \& Childers, 2009). Therefore, it is necessary to clarify and enrich the outcomes of ICT appropriation by disabled people, considering concepts such as selfperceived normalcy (Baker, 2006). The normalcy concept was initially analyzed in the consumption context (Elms \& Tinson, 2012) but could be expanded, as disabled people seek normalcy through their consumption and their daily activities. Therefore, it is important to discover the impact of ICT appropriation on self-perceived normalcy. Finally, it is important to note that to offer meaningful contributions, researchers should not focus on highly specific populations (e.g., people with visual impairment only): they should adopt a broader scope and study several types of disabilities (Childers \& Kaufman-Scarborough, 2009).

Therefore, this study addresses the aforementioned research gaps by examining ICT appropriation by disabled people and investigating its outcomes, especially in terms of self-perceived normalcy. To address this question, an explorative qualitative study based on two focus groups and 10 semi-structured interviews with ICT users with various disabilities was conducted. Thus, this work contributes to the literature in three important ways. First, this paper shows that an existing framework on ICT usage can be applied to disabled users but should be subsequently enriched. Second, it specifically integrates in the framework the consequences of ICT usage and analyzes them in terms of perceived normalcy. Finally, this research studies multiple types of disabilities to offer a valuable framework and a research agenda on ICT appropriation and consequences for disabled people in general.

\section{THEORETICAL BACKGROUND}

\section{Disabled People and the Digital Divide}

The digital divide is defined as the unequal access and usage of ICT worldwide (Eke, 2011). In the least-developed countries, the lack of physical access (insufficient network coverage) and material access are the primary factors that create the digital divide. The challenges of affordability and the lack of digital skills in these countries also contribute to the digital divide (Aikins, 2019). Nevertheless, while a common opinion is that the digital divide is entirely solved when a country's Internet connection rate reaches saturation, recent works proved that the digital divide still exists 
in developed and technologically advanced countries where the network coverage is high (e.g., van Deursen \& van Dijk, 2019). In fact, gaps in the access and usage of ICT might be widening as ICT develops (Mason \& Hacker, 2003). Thus, the divides in Internet skills and type of use continue to expand even after physical access is universal (e.g., Hargittai, 2002). Moreover, even if the physical access becomes universal, like in developed Western Europe countries, inequalities in material access still exist and relate to device/peripheral diversity and maintenance expenses required to maintain the material and the subscriptions (van Deursen \& van Dijk, 2019). Finally, the digital divide replicates existing social inequalities and creates new forms of inequalities and stratifications (Ragnedda \& Muschert, 2013). Several works have studied the differences in the access and usage of ICT among different populations or groups. Several personal characteristics, such as the age (e.g., Ball et al., 2019) or the lack of language skills, for instance in the case of migrants (e.g., Khorshed \& Imran, 2015), and cultural barriers (e.g., Sims, Powell \& Vidgen, 2005) can also explain the reduced access and usage of ICT.

Disabled people fall into one of the main categories of vulnerable individuals who are often digitally impaired (Shishehchi \& Banihashem, 2019). Disabled people in general use less ICT than non-disabled people (Chadwick et al., 2016). Indexes of ICT access and ICT qualitative and quantitative usage are lower for disabled people than non-disabled people (Doh \& Stough, 2010). This result is due to the lack of Internet access, equipment, and auxiliary facilities (Childers \& Kaufman-Scarborough, 2009).

Consequently, disabled people are likely to miss opportunities regarding their personal and professional lives. For instance, they have restricted access to the consumption of online goods and services (Kaufman-Scarborough \& Childers, 2009). Furthermore, lacking ICT access might lead to fewer educational and work opportunities (Chadwick et al., 2016). Thus, disabled users often experience vulnerability, which is defined as a state of powerlessness that arises from an imbalance in online interactions (Baker et al., 2005, p. 134).

\section{ICT Appropriation by Disabled People}

For the general population, ICT appropriation has been analyzed through four sequential stages: motivational access, material access, skills, and usage (van Deursen \& van Dijk, 2015). Motivational access is shaped by the attitude toward the technology. Material access refers to physical access (i.e., having an Internet connection) as well as expenses for hardware, software, and services (van Dijk, 2005). There are two kinds of skills needed to use ICT: medium-related skills, which relate to basic skills required to operate Internet technology and navigate through the Internet, and content-related skills, which refer to literacies to seek information through the Internet and attain one's goal in the most efficient way (van Deursen \& van Dijk, 2010). Finally, actual ICT usage is the final stage of ICT appropriation (van Dijk, 2005). The amount of use and the variety of different usages should be considered (Blank \& Groselj, 2014). Ten types of common usage activities have been identified in the general population: entertainment, commerce, information seeking, socializing, email, blogging, production, mass media, school/work, and vice (e.g., gambling). Each stage of ICT appropriation has its own ground of determination, mainly based on individual characteristics, such as gender, age, education, or revenue (van Deursen \& van Dijk, 2015).

Disabled people are often highly motivated to adopt ICTs, as it can bring more convenience (Childers \& Kaufman-Scarborough, 2009) as well as multiple personal and professional opportunities (e.g., Johnson, 2019). Disabled people are also motivated to adopt ICTs because they can increase happiness and wellbeing despite the isolation and social exclusion (Dennis, Alamanos, Papagiannidis, \& Bourlakis, 2016) and reinforce their sense of self and their role in society by facilitating practical organization of their lives (Elms \& Tinson, 2012). However, disabled individuals still lack equipment and auxiliary facilities that can assist them in using computers and websites (Childers \& KaufmanScarborough, 2009): although they have material access to ICTs, depending on their particular disability, they may lack the skills needed to effectively use Internet and their specific assistive 
technologies (Ritchie \& Blanck, 2003). Being educated and employed, living in urban areas, and having developed ICT skills have been identified as personal factors that favor ICT usage by disabled people (Kim \& Hwang, 2019).

Finally, research on disabled people has tried to determine how disabled people specifically use ICTs. The findings have shown that they use ICTs for personal activities, such as entertainment or communication (Annett-Hitchcock \& Xu, 2015), professional activities, such as working/studying or job searching (Shishehchi \& Banihashem, 2019), and consumption-related activities, such as online shopping (Dennis et al., 2016). Disabled people seem to use ICTs for similar activities to non-disabled people. However, they might have specific ICT usage experiences that should be further investigated (e.g., Yu et al., 2019).

\section{ICT Appropriation Outcomes and Self-Perceived Normalcy}

ICTs might have both positive and negative outcomes for disabled people in terms of self-perceived normalcy. Disabled people use ICTs as a mean to achieve consumer normalcy and live like other consumers. The concept thus reflects how identity is both constructed and maintained for disabled people (Elms \& Tinson, 2012). Consumer normalcy consists of four dimensions (Baker, 2006): being an active part of society (I am here), achieving distinction ( $\mathrm{I}$ am me), demonstrating competence and control (I am in control), and being perceived as an equal in society (I belong). Disabled people strive for normalcy through their daily activities (Mason \& Pavia, 2006).

ICT appropriation could lead to more perceived normalcy among disabled people by helping them to more easily perform daily activities, such as working, connecting with people, entertaining, and shopping. However, the literature is contradictory in this regard: while some authors stress that online activity creates positive outcomes, such as more happiness and wellbeing for disabled people (Dennis et al., 2016), Elms and Tinson (2012) show that using ICTs does not allow them to physically take part in society, which can then reduce the feeling of normalcy. Therefore, it is crucial to develop new insights into the consequences of ICT appropriation by disabled people. To summarize, the research question of this paper is threefold:

(1) What are the barriers to ICT appropriation by disabled people?

(2) What are the ICT usage experiences for disabled people?

(3) What are the consequences of ICT appropriation by disabled people in terms of self-perceived normalcy?

\section{METHOD}

The methodology used in this research followed a phenomenographic approach. Phenomenography considers a phenomenon is the sum of all the qualitatively different ways in which it is seen, experienced, and understood (Marton, 1993). Individual and collective experiences are at the center of this approach (Bruce, 1999). In this study, focus group and semi-structured interviews are combined to gain access to both collective and individual experiences of ICTs.

\section{Sample and Data Collection}

To address the research questions, a qualitative study using focus group and semi-structured interviews was carried out in France. To access the disabled ICT users, the authors relied on the network of a French National Association for Disability. The French context was chosen because France, as most of its European neighbors, has adopted a biopsychosocial disability model (WHO, 2011). The country is therefore preoccupied by adapting the environment to disability situations.

To collect the data, two ICT workshops were organized to attract ICT users. Following Bash's (1987) advice on focus groups, the researchers took the role of moderators. They first created a 
supportive and non-threatening environment. The researchers encouraged all participants to share their view of the topic, they facilitated interactions among members and regularly interjected, commented, summarized dimensions of the topic without interfering too abruptly with the dialogue. During the focus groups, the researchers regularly validated the data with the interviewees. Such dynamic allowed the debate to cover the research questions and also facilitated digressions on the topics interesting and involving for the participants. This procedure allowed for a dynamic exchange with all the participants. The interview guideline may be found in Appendix A.

The final sample consisted of 13 disabled ICT users, divided into two focus groups of six and seven disabled individuals, respectively. The average age was 27.15 years old; eight were males and five were females. The participants had several types of disabilities including sensory disabilities (five respondents), mental illness (three respondents), physical disabilities (four respondents), and a chronic condition (one respondent). The profiles of the respondents are presented in Table 1 below. Only the first letter or the first two letters of the name were kept to ensure anonymity.

Table 1. Background of the focus groups' participants

\begin{tabular}{|c|c|c|c|c|c|}
\hline Name & Age & Gender & Study/Job & Disability & $\begin{array}{c}\text { Disability } \\
\text { Category }\end{array}$ \\
\hline R. & 29, & F & PhD in Communication & Visual impairment & Sensory \\
\hline Y. & 28 & H & Journalist & Motor disability & Physical \\
\hline M. & 19 & F & Japanese studies & Phobia & Mental \\
\hline H. & 20 & F & Assistant manager & Visual impairment & Sensory \\
\hline C. & 28 & M & Entrepreneur & Mental illness (not & Mental \\
\hline J. & 27 & M & PhD in Economics & Phobia & Mental \\
\hline Fr. & 21 & M & Language/Translation studies & Motor disability & Physical \\
\hline L. & 27 & F & Engineer in Environment & Visual impairment & Sensory \\
\hline Fl. & 25 & M & Engineer & Hemiplegia & Physical \\
\hline I. & 34 & M & PhD in Computer Sciences & Motor disability & Physical \\
\hline Ar. & 28 & M & Manager in Public Administration & Visual impairment & Sensory \\
\hline Al.1 & 26 & F & Human resources Assistant & Chronic condition & Chronic condition \\
\hline Ch. & 31 & M & Customer Relationship Manager & Visual impairment & Sensory \\
\hline
\end{tabular}

After conducting the two focus groups, the researchers observed, in coherence with existing literature on focus groups (Nyamati \& Shuler, 1990), that theoretical saturation was not attained. Such effect was specifically caused by the variation of experiences due to the nature of disability.

Therefore, the researchers collected more data and conducted 10 additional in depth semistructured interviews to understand the specific ICT needs and consequences associated with different types of disabilities. Following the principle of methodological triangulation (Thurmond, 2001), the semi-structured interviews allowed the researchers to overcome the limits associated with the focus group methodology. The interviewer attempted to explore areas of confusion, probe analogies, and encourage reflection on experiences (Bruce 1994). Thus, personal interviewing further enlarged the spectrum of disabilities, giving voice to individuals with specific mental illness, such as Asperger syndrome or to people with epilepsy (neurological condition) (cf. Table 2). It also allowed them to 
deepen the analysis of the interaction between a specific disability and ICT usage. Theorical saturation (Strauss \& Corbin, 1998) was attained after the 10 interviews as no more new dimensions of ICT usage emerged during the two last interviews. The interview guide was similar to the one used for the focus group discussion, except some questions specifically addressed to understand the interaction between ICT appropriation and specific disability types (cf. Appendix A). Additional questions were also asked depending on the discussion flow and dynamics. The semi-structured interviews were conducted by one researcher. The sample average age was 28.6 years old; four were females and six were males. Two of the respondents also had participated in the focus group: they insisted on deepening the answers they previously gave in the focus group through a more thorough interview. All interviews and focus groups were recorded and later transcribed.

Table 2. Background of semi-structured interviews' participants

\begin{tabular}{|c|c|c|c|c|c|}
\hline Name & Age & Gender & Studies/Job & Disability & Disability category \\
\hline Ar. (focus group) & 28 & M & $\begin{array}{l}\text { Manager in Public } \\
\text { Administration }\end{array}$ & Visual impairment & Sensory \\
\hline J. (focus group) & 27 & M & $\mathrm{PhD}$ in Economics & Phobia & Mental \\
\hline Li. & 23 & $\mathrm{~F}$ & Logistic studies & Epilepsy & Neurological \\
\hline Le. & 25 & $\mathrm{~F}$ & Political Sciences studies & $\begin{array}{l}\text { Auto immune } \\
\text { disease }\end{array}$ & Chronic condition \\
\hline S. & 25 & M & $\mathrm{PhD}$ in Sciences & Visual Impairment & Sensory \\
\hline $\mathrm{T}$. & 24 & M & Control Management & Motor disability & Physical \\
\hline B. & 28 & M & Project Manager & $\begin{array}{l}\text { Mental illness (not } \\
\text { specified) }\end{array}$ & Mental \\
\hline Me. & 28 & $\mathrm{~F}$ & $\mathrm{PhD}$ in sciences & $\begin{array}{l}\text { Chronic condition } \\
\text { (not specified) }\end{array}$ & Chronic condition \\
\hline V. & 27 & M & Quality Control Manager & $\begin{array}{l}\text { Autism spectrum } \\
\text { disorder }\end{array}$ & Mental \\
\hline Al.2 & 26 & F & Accounting studies & Crohn disease & Chronic condition \\
\hline
\end{tabular}

\section{Data Analysis}

The data analysis followed the phenomenographic approach. In phenomenography, data are coded at the semantic and conceptual levels to find a range of categories that encompass participant conception (Cossham, 2017). The analysis is interactive rather than sequential and allowed the research design to evolve over the course of the research (Cossham, 2017). Therefore, the data analysis progressed in several stages, during which the authors increased the level of generalization (Mantere, 2008).

Regarding the process of analysis, the interview transcripts were first read. In the second stage, the authors examined the data to generate categories in line with the open coding technique system recommended by Strauss and Corbin (1998). The constant comparison of codes was used. A process of dynamic construction and deconstruction was put in place to create codes that largely corresponded to the issues covered during the interviews. Recurrent reading of ICT literature also allowed the codes to be redefined. Such iterations allowed the researchers to cover and delimitate the dimensions associated with disabled individuals' ICT experience (Cossham, 2017).

During the coding process, the three authors coded independently and then compared the codes, which allowed the consolidation of categories. The final level of analysis involved reinvesting the 
literature, merging existing knowledge on disabled people's ICT appropriation with the data gathered from the exploratory research, and identifying new variables (cf. Table 3 ).

Table 3: Example of the Coding Procedure Used by the Researchers

\begin{tabular}{|c|c|c|c|c|}
\hline & Existing codes & New querying & Codes refutation & New codes \\
\hline $\begin{array}{c}\text { Existing } \\
\text { literature }\end{array}$ & Professional usage & Decrease normalcy & Vice (usage) & \\
\hline Field & Professional usage & $\begin{array}{c}\text { Amplification of } \\
\text { symptoms }\end{array}$ & & Disability compatibility \\
\hline
\end{tabular}

\section{FINDINGS}

\section{ICT Perceived Barriers and Facilitators}

\section{Investment to Find the Right Device}

Disabled individuals sometimes have trouble finding the right device adapted to their condition. Ch. (visual impairment) invested considerable time in finding what he really needed: "You can find information, but you have to do intensive researches. Sometimes I learn something by discussing with others and I tell myself that if I had known this before it would have been easier for me."

Paradoxically, individuals at times feel overwhelmed by the mass of information. Ar. (visual impairment) and now an expert on ICTs specific to visually impaired people, promotes device usage through specific social networks to help individual choose adapted devices: "I created a specific group for visually impaired individuals. In this group we exchange about useful devices." The outcomes of ICT appropriation are, therefore, dependent on the initial time disabled individuals will invest to determine what is really adapted to them. The investment consists less of the acquisition of the needed device or software, but more of the access to information about the existing solutions facilitating access to ICTs and decision-making on the most adapted solution.

\section{Compatible Material Access}

A type of disability might generate specific needs as well as specific issues regarding ICT usage. While Y. and F. (motor disability) need to have lightweight devices to keep their movements free, L. (epilepsy) is sensitive to the colors used on websites, as bright colors can generate an epileptic seizure. Inverted contrasts bother visually impaired individuals, such as R. (visual impairment). Moreover, $\mathrm{J}$. is concerned by the quantity of advertisements and information that he finds on a webpage, as anxiety can emerge when he perceives too many flashing ads. Finally, because of her social phobia, M. (mental illness) cannot look at pictures of crowds on the Internet: "When I see a crowd, I can't go any further."

Thus, the devices that are used by disabled people to access the Internet must have specific characteristics (i.e., in terms of size, weight, or design) depending on their disability. Moreover, the way the content and the information are presented on webpages also has different impacts according to the specific disability. In the absence of an adapted automated solution, many disabled users rely on human assistance. The compatibility of the device with the ICT and the format of the ICT with the disability condition are likely to influence ICT appropriation by disabled people. 


\section{Learning and Adaptation Skills}

Learning costs exist if people want to use ICTs adequately and experience their benefits. Such learning costs might be amplified by a disability. This is true for $\mathrm{H}$. (visual impairment), who needs to adapt herself to specific ICTs for visually impaired people (easy braille) as well as to classic ICTs that she have to use in her everyday life: "At the beginning, I had several issues with easy drive. The screen was not working. It was discouraging, but I really want to learn." $\mathrm{H}$. also uses the help of her father when she can have autonomous access to the device. How disabled individuals engage with the learning and adaptation costs affects the extent to which they take advantage of ICTs. These adaptation skills depend directly on the initial motivation to learn and master a new software or have access to an ICT.

ICTs also facilitate the general access to knowledge in class and to have equal knowledge access conditions as non-disabled students. Ar. (visual impairment) for example, had access to audiobooks at the end of his studies and found that more practical than "braille books" which were really heavy: "When I was taking the braille book, I needed 18 braille volumes to have the equivalent of a normal class book." As soon as Ar. realized that audiobooks and easy braille represent economies of time and space (braille books being very heavy), he became more engaged in the learning process and could succeed better in using the new technology. Thus, adaptation to the new ICT is directly related to the perceived effectiveness and the perceived need to learn the new ICT.

\section{Types of Usage}

\section{Educational Usage}

Individuals with disabilities use ICTs for specific education needs. ICTs are reinforcing education accessibility by facilitating individuals to take notes and to catch up on the learnt material beyond the classroom. ICTs also clearly facilitate the organization of the curriculum. With the help of new technologies, students can organize exam arrangements. Several types of ICTs are usually mobilized for exam arrangements, such as software to correct the language and improve the visibility. Computers or tablets are often used to improve hand dexterity: "They give me a tablet so I can pass my exams," explained S. (Visual impairment).

\section{Professional Usage}

Individuals with disabilities also use ICTs to facilitate their workplace integration and have access to recruitment tools. Disabled individuals largely mobilize ICTs to have access to disabilityspecific employment networks and forums, as it allows them to ease and accelerate the integration in the workplace. Local companies are required to have $6 \%$ of disabled individuals in their total workforce. Therefore, a specific online network dedicated to the recruitment of disabled people has been implemented. This is the case for L. (chronic condition), who specifically searches online if the company she wants to work for is disability friendly. She states: "Online, I tick the disability box whenever I can do it. For example, the European parliament has that kind of box. For now, I'm waiting (for their answer)."

Moreover, workplace adjustments often involve ICTs. For example, M. (chronic condition) can telecommute and avoid the extreme exhaustion caused by her disability condition, thanks to ICTs. M. has her workstation installed at home, which is connected to her workplace. She also remotely gives instructions to an intern she recruited at work.

\section{Community Usage}

Apart from the classical social network usage, disabled individuals also use ICTs to access disabled individuals' communities: "Sometimes, I have contact, thanks to that. I talk about my hobbies; I look for contacts. It's the community aspect that is interesting" ( $\mathrm{Cl}$., mental and motor disability). It is also a way to be among individuals who are aware of disability issues: "We can find communities. They post video on disability. They are interested in several types of disability" (Y., motor disability). 
Thanks to online communities, disabled individuals do not feel alone and talk about their situation: "It's pleasant to know that you are not the only one questioning yourself" (Y., motor disability). Communitarian or social use of ICTs is the main contributor to the emotional well-being of disabled people. Surprisingly, disabled users prefer to disclose their disabilities online to find people like them or understanding of them, rather than hide behind anonymous avatars.

\section{Medical Usage}

ICTs are used to increase knowledge of their situation and even to diagnose their condition: "I look for information to complete what my doctor tells me during my medical appointments" $(\mathrm{Cl}$., mental and motor disability). Moreover, apart from the diagnosis, disabled individuals complete the information on how they can adapt to their condition. Ar. (visual impairment) is, for example, very active in trying to find tools granting better access to goods and services. He uses online reviews to understand exactly what kinds of products he can try: "Most of the time, it's informal. There is no official tool that points out the best software (for my needs). It's through social exchanges. You can find forums, but you have to do intensive research." For many disabled users, especially with cognitive and chronic conditions, ICTs helped them to find, understand, and accept their diagnosis.

\section{Optimization of Daily Need Fulfilment}

ICTs help disabled individuals to meet their daily needs. Disabled individuals do their grocery shopping online and complete the necessary administrative procedures on the Internet: "I have two examples: I use the drive to do my shopping; it's essential for me. It allows me to take less time to do the shopping. Then, if we look at administrative procedures, now everything is online. It's really convenient" (F., motor disability). For F., online shopping is essential because his motor disability does not allow him to carry out his shopping alone.

Nevertheless, even if online shopping is highly convenient for disabled individuals, they point out that it is not adapted for all products. Disabled users insist that it is necessary to go to the mall for specific products, as online shopping may not guarantee satisfaction: "Clothes? When I buy them online, I'm never sure that it's going to suit me" (L., visual impairment). "Fruits and vegetables? I prefer to choose them" (Y., motor disability).

\section{Advantages of ICT Usage}

\section{Time Control}

ICTs allow disabled individuals to gain more control of their time. Thanks to ICTs, they do not lose time because of an unexpected lack of accessibility. Saving this time allows them to have more time for their personal leisure and activities. L. (visual impairment) explained: "And we save time. When I go to the supermarket, I know what I need. I don't want to do all the aisles. It makes me crazy, and it's exhausting. Even if I go three times in the week, I need an hour to go and an hour to come back. On the Internet, I have control of my time." F. (motor disability) adds: "It helps me to organize myself adequately and to be able to study and work at the same time. It reduces useless travels."

\section{Access to Similar People}

ICTs increase the impression of belonging to a disability social group by helping individuals finding others who share the same disability. V. (autism spectrum disorder) insisted: "It gave me the occasion to meet people who behave like me". H. (visual impairment) added: "Without social networks, I don't know how to meet disabled individuals like me. It helps me connect with disability charity companies."

Such occasion to meet similar others also allows individuals to become activists in the disability community and generally raise society's awareness of disabilities. A. (visual impairment) explained: "We have this community in which we talk about devices adapted to visually impaired people. We really try to promote that community." 


\section{Autonomy}

By helping disabled individuals to meet their daily needs, ICTs increase their autonomy. They do not need external assistance to perform tasks. Ch. (visual impairment) claimed: "With this X mobile application, I'm able to know if the light is on in my room. It avoids me to sleep with the light on the whole night or to have someone turning it off for me." It also reduces the feeling of anxiety engendered by an unexpected lack of accessibility and a subsequent lack of autonomy. "Stores: when I don't know them by heart, it's a nightmare!" claimed J. (mental illness).

\section{Lack of Public Space Accessibility Compensation}

ICTs compensate for the lack of accessibility of public spaces, such as city centers. In some cities, disabled individuals feel excluded: "The city center is not accessible. I prefer to shop online" (J., mental illness). The public space is not organized to optimize their movements. L. (visual impairment) explained: "In my town, all the shops are moved to the periphery. We need to travel more than 45 minutes to find the useful ones."

\section{Risks of ICTs}

\section{Unexpected Vulnerability}

For some types of disabilities, ICTs may create new forms of vulnerability, especially socially. Individuals may start feeling isolated from others: "Suddenly, I started to overuse social networks, and it had impacts on my relationships with real people" (F., motor disability). J. (mental illness) described the feeling of extreme vulnerability experienced online: "With a mental illness, you can find yourself in a real state of weakness. You can find predators on the Internet, and the person is isolated in front of her screen and doesn't have the possibility to answer in an appropriate way."

\section{The ICT Dependence Paradox}

Disabled individuals are afraid of not being able to disconnect themselves from ICTs, while at the same time they need it to be able to facilitate their daily life. Such situation is not perceived as caused by their disability but is identified as amplified by this condition, as disabled people need ICTs to gain autonomy. Al. (chronic illness) stated that she started to feel she was spending too much time online: "I started having a feeling of lack, and there was no lack!!!" L. (visual impairment) added: "It is an evolution of the society that facilitates our life and creates dependence at the same time."

\section{DISCUSSION}

The results show that ICT access and usage are still not a given for disabled people. Disabled users have to invest in finding and acquiring the right technology that permits further use of ICTs; due to their disabilities, they generally have to adapt and learn how to use ICTs. They also have specific usage of ICTs due to their disability. Finally, the outcomes of ICT appropriation are not always advantageous. While ICTs rightfully play a major role in gaining control, they may also lead to dependence and anxiety.

First, the literature on ICT appropriation identifies motivational access as a major influencer of ICT access (material access) and usage (van Deursen \& van Dijk, 2015). In this research, the authors show that disabled individuals' motivational access is tainted by the effort and time they have to invest to find the adapted device for their disability situation. Regarding material access, apart from the importance of physical access that is already documented by ICT and disability research (Doh \& Stough, 2010; van Deursen \& van Dijk, 2015), the authors show the importance of the compatibility between the disability needs, the device, and the information. Thus, ICTs should be accessible in terms of format and layout. Finally, regarding skills, apart from medium and content skills (Ritchie 
\& Blanck, 2003), disabled individuals need to show learning and adaptation skills to ensure that the device accommodates their disability.

Second, existing research on the topic of ICT usage shows that disabled people use ICTs for different matters (Childers \& Kaufman-Scarborough, 2009): personal (e.g., entertainment, communication), professional (e.g., looking for job announcements or working), and consumptionrelated activities. The authors find that the professional and educational dimensions are strong motivating factors of ICT appropriation. Furthermore, the authors found two very important ICT usages for disabled people: social (i.e., community usage) and medical (i.e., learning about one's condition and possible solutions) usages. These usages are very specific and crucial to disabled users, as they allow them to be themselves (i.e., establish their identity, understand their condition, and accept it) and to become part of a community of similar users. This result is in line with recent research highlighting how ICTs allow identity to be restored for marginalized communities (Young, 2018).

Third, the authors found that ICTs have controversial outcomes for disabled individuals. The literature shows that ICTs can lead to convenience and autonomy for disabled individuals (KaufmanScarborough \& Childers, 2009). In this research, the authors identified a positive impact on disabled individuals' perceived normalcy (Elms \& Tinson, 2012). ICTs can improve their global inclusion in society by allowing them to be more active in their education and their personal and professional life (e.g., Johnson, 2019). In parallel, ICTs can allow them to achieve distinction by favoring social action in disability communities. ICTs also give disabled individuals the feeling of being in control by allowing more autonomy and giving them control of their time. They also increase the perception of being considered equals. Some works also show that ICT usage can have negative outcomes for disabled people, such as isolation and social exclusion (Darcy et al., 2019; Elms \& Tinson, 2012). Accordingly, the research shows that ICTs can reduce the perceived normalcy of disabled individuals. They can create a dependence paradox, as disabled individuals can be perceived to be more ICT dependent than their valid counterparts due to the convenience it can bring them. ICTs also generate a backlash effect, as disability symptoms may be amplified because of ICTs, especially regarding mentally ill individuals.

Finally, while existing studies on ICT appropriation have identified gender, age, incomes, education, and internet experience as moderators of how users experience ICTs (van Deursen \& van Dijk, 2015), this research highlights the role that disability type plays in ICT appropriation and outcomes. This is important, as the majority of ICT and disability research focuses on one disability type (Chadwick et al., 2016) where the global role of the disability type should be considered (Scholtz et al., 2017).

\section{Model and research agenda}

An integrative model of ICT appropriation by disabled people is offered (Figure 1) based on the exploratory findings of this research and on variables previously identified in the literature. This conceptual model could be used to develop further research on ICT appropriation by disabled individuals.

\section{ICT Use Barriers}

In France, having access to ICTs is less a matter of financial resources (e.g., disabled users can benefit from a technical education program for a cost of up to $3850 €$ ) and is more a matter of being informed about an existing solution, which would fit their needs. This is specifically important to disabled users with mental health issues (e.g., Rosen et al., 2013): it is harder for them to identify solutions that might help them to use ICTs in a more effective way. Thus, further research aims are twofold: first, to identify the specific technological needs of disabled users with different disabilities to be able to segment and design tools and solutions applicable to a variety of disabled users; and second, to identify the ways to reach the concerned users. 
Figure 1. Presents an integrative framework of ICT appropriation by disabled users, adapted from van Deursen and van Dijk (2015).

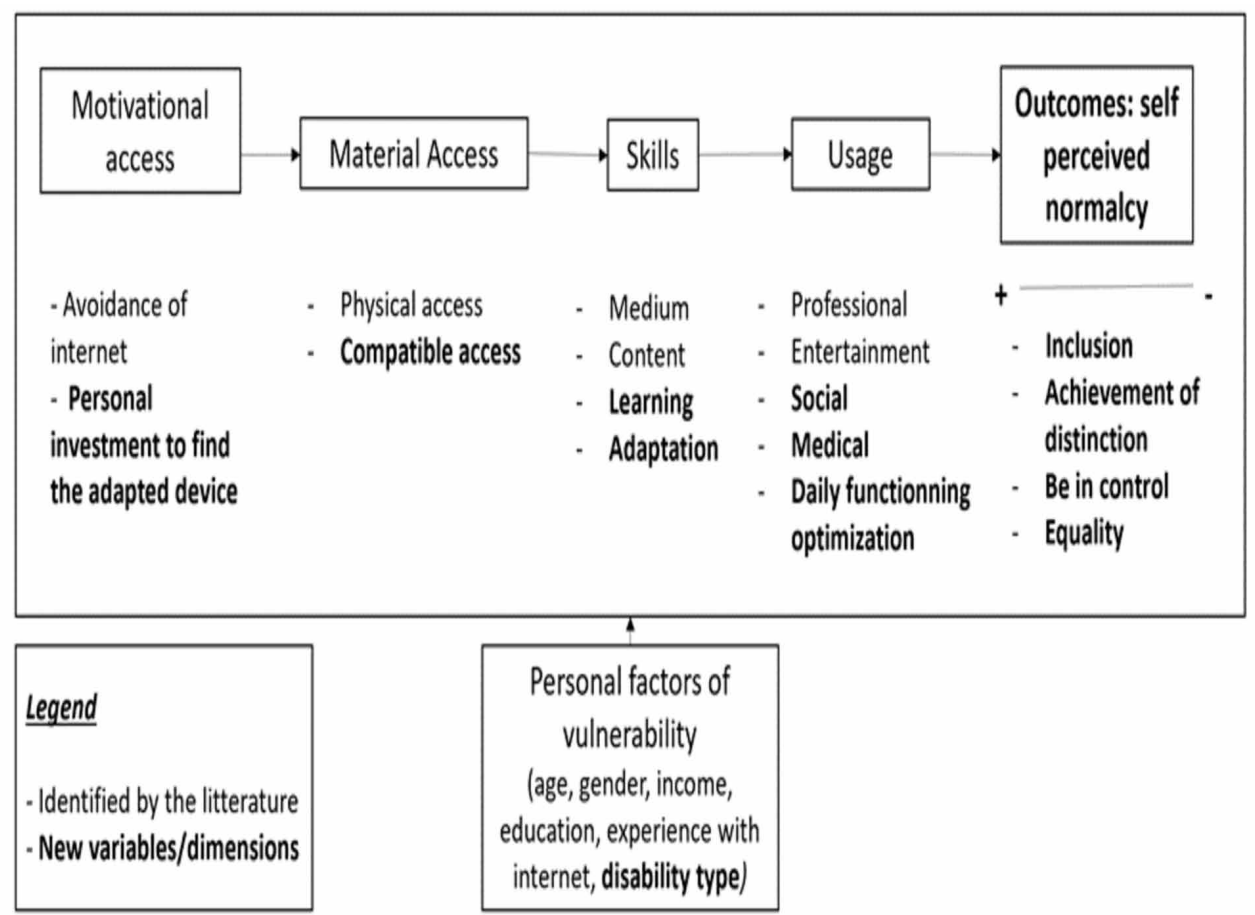

Furthermore, to be able to bridge the digital divide for the disabled users, further research should deepen the knowledge on the relationship between the environmental and psychological factors and the consequent ICT appropriation. Thus, it is important to understand how to help disabled individuals act on their ICT appropriation by making them believe that ICT can improve their lives (Marks \& Allegrante, 2005). Informational campaigns can propagate available solutions for better ICT use.

\section{Type of ICT Usage}

The ICT usage of disabled users depends largely on their ability to learn how to use ICTs, as learning is more difficult for them. On the other hand, a successful apprenticeship of ICTs can lead to a better integration and success of disabled users in an educational or work environment. The facilitators of ICT access, devices, and software, as well as ICTs themselves should be easy to learn and appropriate for disabled users. Therefore, the key to personal and professional well-being lies in their capacity to grasp and appropriate the new ICTs. Ideally, disabled users should become lead users involved in co-creation (De Couvreur \& Goossens, 2011). Depending on the disability, the learning process should be adapted to meet their final use and empowerment goals.

While the uses of ICTs by disabled users do not differ from those of the non-disabled (i.e., communication, consumption, education, and work), acquiring information and support related to disabilities is immensely important to them. Thus, it is critical to understand what kind of information and in which format is the most helpful to disabled users (e.g., online platform, mobile app, or AI assistant). Furthermore, it is important to investigate how to facilitate and stimulate the creation of online communities for disabled but also by disabled users. 


\section{Effects of ICT Usage}

Finally, it is important to investigate what social and legal levers should be put in place to ensure that ICT use actually increases the self-perceived normalcy for the disabled users and does not lead to social exclusion, dependence, and anxiety issues. It is true that ICT can increase the independence and participation of disabled people in society. Initiatives in that perspective allow disabled people to gain independence and be active citizens of society. Nevertheless, increased ICT use has a negative impact as well. First, Internet communication leads to dependency and even addiction (Kuss \& Lopez-Fernandez, 2016). Moreover, constant comparison with biased representations of others' lives can create in ICT users a sense of failure and self-depreciation (Niemz et al., 2005). This negative effect is true for all Internet users and can be specifically destructive to the well-being and social participation of disabled users.

\section{Limitations of the Study}

This research has a number of limitations. First, some disabilities might have had an impact on the focus group dynamic; some participants in the focus group categorically refused to speak. Some disabled individuals (e.g., hearing impaired) may have been hindered from participating in the study due to the chosen methodology. Furthermore, the proposed conceptual model (Figure 1) was created using a qualitative methodology with a restricted sample. Further research should enrich this model with a larger sample and should test it with a quantitative methodology to increase the generalization of the findings.

Furthermore, the sample for this research was composed of highly educated individuals; thus, the impact of the social origin on ICT appropriation and outcomes could not be addressed. Moreover, the interviewed sample consisted of young adults, and the age impact was, therefore, not accounted for. Finally, the sample consisted of French citizens and studied the French context, which, contrary to Eastern European countries, is more advanced in reducing the digital divide (Negreiro, 2015). Therefore, future research should address different economic and social contexts and involve crosscountry studies.

\section{CONCLUSION}

This qualitative study explored ICT appropriation and the outcomes for disabled individuals and contributed to the literature in a number of ways. First, a rich model of ICT appropriation and outcomes among disabled individuals and a research agenda were proposed. Second, the qualitative study accounted for a multitude of disabilities and showed that although ICT appropriation is disability dependent, some barriers and facilitators are common to all disabled individuals and, therefore, should be considered by policymakers. Third, this research highlighted new variables, whose role in ICTs has not yet been identified. Finally, both positive and negative outcomes of ICT usage were considered.

In addition to the research agenda offered in this study, other directions could be investigated to improve knowledge on disabled people ICT appropriation. First, research could identify the specific technological needs of users with various disabilities, in order to create solutions that respond to the needs of most different disabled users (Fernandez-Batanero, Cabero-Meneses \& Lopez-Almenara, 2019). Second, the communication issues should be addressed to identify the appropriate way to inform disabled users' on accessible ICT solutions. Third, it is important to explore the role of perceived self-efficacy on the motivation to learn new ICT and advance one's use of available ICT. Furthermore, as online communities for and by disabled users have a crucial role in helping disabled users in various aspects of their life (e.g., Annett-Hitchcock \& Xu, 2015), future research should study how these virtual communities emerge, develop, and support disabled users in their ICT usage and in their daily life. Finally, future research could explore the negative effect of ICT usage on disabled users' well-being and self-image. 


\section{REFERENCES}

Aikins, S. K. (2019). Determinants of Digital Divide in Africa and Policy Implications. International Journal of Public Administration in the Digital Age, 6(1), 64-79. doi:10.4018/IJPADA.2019010104

Annett-Hitchcock, K., \& Xu, Y. (2015). Shopping and virtual communities for consumers with physical disabilities. International Journal of Consumer Studies, 39(2), 136-144. doi:10.1111/ijcs.12161

Baker, S. M. (2006). Consumer normalcy: Understanding the value of shopping through narratives of consumers with visual impairments. Journal of Retailing, 82(1), 37-50. doi:10.1016/j.jretai.2005.11.003

Baker, S. M., Gentry, W., \& Rittenburg, T. L. (2005). Building understanding of the domain of consumer vulnerability. Journal of Macromarketing, 25(2), 128-139. doi:10.1177/0276146705280622

Ball, C., Francis, J., Huang, K.-T., Kadylak, T., Cotten, S. R., \& Rikard, R. V. (2019). The Physical-Digital Divide: Exploring the Social Gap Between Digital Natives and Physical Natives. Journal of Applied Gerontology, 38(8), 1167-1184. doi:10.1177/0733464817732518 PMID:29165009

Basch, C. (1987). Focus group interview: An underutilised research technique for improving theory and practice in health education. Health Education Quarterly, 14(4), 411-448. doi:10.1177/109019818701400404 PMID:3319971

Blank, G., \& Groselj, D. (2014). Dimensions of Internet use: Amount, variety, and types. Information Communication and Society, 17(4), 417-435. doi:10.1080/1369118X.2014.889189

Bruce, C. (1999). Phenomenography: Opening a new territory for library and information science research. New Review of Information and Library Research, 5(1), 31-47.

Chadwick, D. D., Quinn, S., \& Fullwood, C. (2016). Perceptions of the risks and benefits of Internet access and use by people with intellectual disabilities. British Journal of Learning Disabilities, 45(1), 21-31. doi:10.1111/ bld. 12170

Childers, T. L., \& Kaufman-Scarborough, C. (2009). Expanding opportunities for online shoppers with Disabilities. Journal of Business Research, 62(5), 572-578. doi:10.1016/j.jbusres.2008.06.017

Commuri, S., \& Ekici, A. (2008). An enlargement of the notion of consumer vulnerability. Journal of Macromarketing, 28(2), 183-186. doi:10.1177/0276146708316049

Cossham, A. F. (2017). An evaluation of phenomenography. Library and Information Research, 41(125), 17-31. doi:10.29173/lirg755

Darcy, S., Yerbury, H., \& Maxwell, H. (2019). Disability citizenship and digital capital: The case of engagement with a social enterprise telco. Information Communication and Society, 22(4), 538-553. doi:10.1080/136911 8X.2018.1548632

De Couvreur, L., \& Goossens, R. (2011). Design for (every) one: Co-creation as a bridge between universal design and rehabilitation engineering. CoDesign, 7(2), 107-121. doi:10.1080/15710882.2011.609890

Dennis, C., Alamanos, E., Papagiannidis, S., \& Bourlakis, M. (2016). Does social exclusion influence multiple channel use? The interconnections with community, happiness, and well-being. Journal of Business Research, 69(3), 1061-1070. doi:10.1016/j.jbusres.2015.08.019

Doh, S., \& Stough, R. R. (2010). Analysis of the impact of the perceived usefulness of ICT on the digital divide between disabled and non-disabled people in South Korea. International Review of Public Administration, 14(3), 53-70. doi:10.1080/12294659.2010.10805161

Dubost, N. (2018). Disability and consumption: A state of the art. Recherche et Applications en Marketing, 33(2), 75-92. doi:10.1177/2051570718764882

Eke, D. O. (2011). ICT Integration in Nigeria: The Socio-Cultural Constraints. International Journal of Technology and Human Interaction, 7(2), 21-27. doi:10.4018/jthi.2011040103

Elms, J., \& Tinson, J. (2012). Consumer vulnerability and the transformative potential of Internet shopping: An exploratory case study. Journal of Marketing Management, 28(11/12), 1354-1376. doi:10.1080/026725 7X.2012.691526 
Fernández Batanero, J. M., López Meneses, E., \& Cabero Almenara, J. (2019). Knowledge and degree of training of primary education teachers in relation to ICT taught to disabled students. British Journal of Educational Technology, 50(4), 1961-1978. doi:10.1111/bjet.12675

Grammenos, S. (2018). European comparative data on Europe 2020 and People with disabilities, Final Report. European Network of Academic Experts in the Field of Disability.

Hargittai, E. (2002). Second-level digital divide: Differences in people's online skills. First Monday, 7(4), 7. doi:10.5210/fm.v7i4.942

Johnson, M. R. (2019). Inclusion and exclusion in the digital economy: Disability and mental health as a live streamer on Twitch.tv. Information Communication and Society, 22(4), 506-520. doi:10.1080/136911 8X.2018.1476575

Kaufman-Scarborough, C., \& Childers, T. L. (2009). Understanding markets as online public places: Insights from consumers with visual impairments. Journal of Public Policy \& Marketing, 28(1), 16-28. doi:10.1509/ jppm.28.1.16

Khorshed, A., \& Imran, S. (2015). The digital divide and social inclusion among refugee migrants: A case in regional Australia. Information Technology \& People, 28(2), 344-365. doi:10.1108/ITP-04-2014-0083

Kim, K. M., \& Hwang, J. H. (2019). Exploring gaps in the online economic inclusion of persons with disabilities in Korea. Information Communication and Society, 22(4), 570-581. doi:10.1080/1369118X.2018.1545039

Kuss, D. J., \& Lopez-Fernandez, O. (2016). Internet addiction and problematic Internet use: A systematic review of clinical research. World Journal of Psychiatry, 6(1), 143-176. doi:10.5498/wjp.v6.i1.143 PMID:27014605

Mantere, S. (2008). Role expectations and middle manager strategic agency. Journal of Management Studies, 45(2), 294-316.

Marks, R., \& Allegrante, J. P. (2005). A review and synthesis of research evidence for self-efficacy-enhancing interventions for reducing chronic disability: Implications for health education practice (part II). Health Promotion Practice, 6(2), 148-156. doi:10.1177/1524839904266792 PMID:15855284

Marton, F. (1993). On awareness. Unpublished manuscript.

Mason, M., \& Pavia, T. (2006). When the family system includes disability: Adaptation in the marketplace, roles and identity. Journal of Marketing Management, 22(9-10), 1009-1030. doi:10.1362/026725706778935637

Mason, S. M., \& Hacker, K. L. (2003). Applying communication theory to digital divide research. ITandSociety, $1(5), 40-55$.

Michel-Verkerke, M. B., Schuring, R. W., \& Spil, T. A. M. (2005). USE IT to Create Patient-Relation Management for Multiple Sclerosis Patients. International Journal of Technology and Human Interaction, 1(4), 58-75. doi:10.4018/jthi.2005100104

Negreiro, M. (2015). Bridging the digital divide in Europe. Briefing. European Parliament Research Service.

Niemz, K., Griffiths, M., \& Banyard, P. (2005). Prevalence of pathological Internet use among university students and correlations with self-esteem, the General Health Questionnaire (GHQ), and disinhibition. Cyberpsychology \& Behavior, 8(6), 562-570. doi:10.1089/cpb.2005.8.562 PMID:16332167

Nyamathi, A., \& Shuler, P. (1990). Focus group interview: A research technique for informed nursing practice. Journal of Advanced Nursing, 15(11), 1281-1288. doi:10.1111/j.1365-2648.1990.tb01743.x PMID:2269750

Ragnedda, M., \& Muschert, G. W. (2013). The Digital Divide: The internet and social inequality in international perspective. Routledge. doi:10.4324/9780203069769

Ritchie, H., \& Blanck, P. (2003). The promise of the Internet for disability: A study of on-line services and web site accessibility at Centers for Independent Living. Behavioral Sciences \& the Law, 21(1), 5-22. doi:10.1002/ bsl.520 PMID:12579615

Rosen, L. D., Whaling, K., Rab, S., Carrier, L. M., \& Cheever, N. A. (2013). Is Facebook creating "iDisorders"? The link between clinical symptoms of psychiatric disorders and technology use, attitudes and anxiety. Computers in Human Behavior, 29(3), 1243-1254. doi:10.1016/j.chb.2012.11.012 
Scholz, F., Yalcin, B., \& Priestley, M. (2017). Internet access for disabled people: Understanding socio-relational factors in Europe. Cyberpsychology (Brno), 11(1), 4. doi:10.5817/CP2017-1-4

Shishehchi, S., \& Banihashem, S. Y. (2019). JRDP: A Job Recommender System Based on Ontology for Disabled People. International Journal of Technology and Human Interaction, 15(1), 85-99. doi:10.4018/ IJTHI.2019010106

Sims, J., Powell, P., \& Vidgen, R. (2005). eLearning and the Digital Divide: Perpetuating Cultural and SocioEconomic Elitism in Higher Education. European Conference on Information Systems Proceedings, Paper 117.

Strauss, A., \& Corbin, J. (1998). Basics of qualitative research: Procedures and techniques for developing grounded theory. Sage Publications.

Thurmond, V. A. (2001). The point of triangulation. Journal of Nursing Scholarship, 33(3), 253-258. doi:10.1111/ j.1547-5069.2001.00253.x PMID:11552552

Toomey, R. (2001). Schooling Issues Digest No 2: Information and Communication Technology for Teaching and Learning. Retrieved March 22, 2005, Retrieved from: http://www.dest.gov.au/schools/publications/2001/ digest/technology.htm

van Deursen, A. J., \& van Dijk, J. A. (2010). Measuring Internet skills. International Journal of Human-Computer Interaction, 26(10), 891-916. doi:10.1080/10447318.2010.496338

van Deursen, A. J., \& van Dijk, J. A. (2015). Toward a multifaceted model of internet access for understanding digital divides: An empirical investigation. The Information Society, 31(5), 379-391. doi:10.1080/01972243. 2015.1069770

van Deursen, A. J., \& van Dijk, J. A. (2019). The first-level digital divide shifts from inequalities in physical access to inequalities in material access. New Media \& Society, 21(2), 354-375. doi:10.1177/1461444818797082 PMID:30886536

van Dijk, J. A. (2005). The deepening divide: Inequality in the information society. Sage Publications.

World Health Organization. (2011). World Report on Disability: Summary. Retrieved from: https://www.who. int/disabilities/world_report/2011/report.pdf

Young, A. G. (2018). Using ICT for social good: Cultural identity restoration through emancipatory pedagogy. Information Systems Journal, 28(2), 340-358. doi:10.1111/isj.12142

Yu, H., Goggin, G., Fisher, K., \& Li, B. (2019). Introduction: Disability participation in the digital economy. Information Communication and Society, 22(4), 467-473. doi:10.1080/1369118X.2018.1550525 


\section{APPENDIX A.}

\section{Interview guideline (focus group and semi- structured interviews)}

\section{Topic 1: General questions about ICT usage and appropriation}

ICT stands for Information and Communication Technologies and includes devices and software used to create and disseminate information and communicate with other people.

- What type of ICT do you use?

- How often do you use ICT?

Topic 2: Motivations to use ICT

- Why do you use ICT?

- Is it easy for you to use ICT?

- What kind of difficulties do you encounter when using ICT?

- Do you think you depend on ICT in some way?

\section{Topic 3: ICT and disability}

- What do you think are the advantages of ICT usage for a disabled person?

- What do you think are the drawbacks of ICT usage for a disabled person?

Topic 4: Internet use experience and satisfaction

- Are you satisfied with your ICT Usage? Why?

- What does ICT bring to you?

Additional questions evolved from the discussion

- How do you find information about ICT facilitators?

- How do you learn how to use ICT?

- Do you interact more often online or offline? Why?

- How do you feel when you communicate on a forum? Browse social media?

- Do you prefer buying online or offline?

Additional questions specific to semi-structured interviews

- The impact of the specificity of their disability on ICT usage. The specific opportunities and drawbacks generated by the disability.

- Description of the situation where they specifically encounter barriers.

- For individuals with psychic disability: vulnerability generated by ICT.

- The online community they belong to and what it brings. 
Sarah Richard is an assistant professor at EM Strasbourg business school. Her main research focuses on disability employment policies and stigma related decision-making process. Her research has been published in French and international journal such as European Journal of Industrial Relations and Employee Relations. She also contributed to book chapters and participated at several international conferences.

Daria Plotkina is an Associate Professor of Marketing in EM Strasbourg Business School at the University of Strasbourg, France. She received her PhD in Marketing and Information Systems from the University of Strasbourg. Her research interests include digital marketing, international consumer behavior, ICT use, and online communication. Daria Plotkina published in Journal of Business Research, Journal of Retailing and Consumer Services, contributed to book chapters, and communicated at numerous international conferences.

Hélène Saurel teaches marketing and sales at the University of Tours, France. She received her PhD in Marketing from Paris Dauphine University, France. Her research interests include consumer behavior, digital marketing, and the Marketing Department. Her research has been published in French and international journals such as Journal of Retailing and Consumer Services. 